\title{
Pudendal Nerve Entrapment Syndrome due to a Ganglion Cyst: A Case Report
}

\author{
Jae Wook Lee, $\mathrm{MD}^{1}$, Sung-Moon Lee, $\mathrm{MD}^{2}$, Dong Gyu Lee, $\mathrm{MD}^{1}$
}

Departments of ${ }^{1}$ Rehabilitation Medicine and ${ }^{2}$ Diagnostic Radiology, Keimyung University School of Medicine, Daegu, Korea

Pudendal nerve entrapment syndrome is an unusual cause of chronic pelvic pain. We experienced a case of pudendal neuralgia associated with a ganglion cyst. A 60 -year-old male patient with a tingling sensation and burning pain in the right buttock and perineal area visited our outpatient rehabilitation center. Pelvis magnetic resonance imaging showed the presence of multiple ganglion cysts around the right ischial spine and sacrospinous ligament, and the pudendal nerve and vessel bundle were located between the ischial spine and ganglion cyst at the entrance of Alcock's canal. We aspirated the lesions under ultrasound guidance, and consequently his symptoms subsided during a 6-month follow-up. This is the first report of pudendal neuralgia caused by compression from a ganglion cyst around the sacrospinous ligament.

Keywords Pudendal nerve entrapment syndrome, Pudendal neuralgia, Ganglion cysts, Ultrasonography

\section{INTRODUCTION}

Pudendal nerve entrapment syndrome (PNE) is an unusual cause of chronic pelvic pain, in which the pudendal nerve is entrapped or compressed. Pudendal neuralgia is a symptom caused by pudendal neuropathy such as bowel, bladder, and sexual dysfunction, in addition to pain in the distribution of the pudendal nerve that is exacerbated on sitting.

The pudendal nerve arises from the sacral plexus, and comprises the S2, S3, and S4 segments. It is a mixed nerve that supplies sensation to genitalia such as the penis, scrotum, clitoris, and labia, and innervates muscles of the perineum and pelvic floor. The nerve exits through the greater sciatic foramen, crossing the ischial spine, the sacrospinous ligament, and the sacrotuberous ligaments [1-4]. Along this course, there are three common locations of nerve entrapment: between the sacrotuberal and sacrospinous ligaments, within the pudendal canal, and while crossing the falciform process of the sacrotuberal ligament [2].

The diagnosis of PNE is essentially clinical. There are no pathognomonic signs or specific tests [2]. The 'Nantes criteria' are the diagnostic criteria of PNE, but they are not sufficient for all clinical situations [5]. Therefore, a detailed pain history and physical examination are

Received August 17, 2015; Accepted October 19, 2015

Corresponding author: Dong Gyu Lee

Department of Physical Medicine \& Rehabilitation, Keimyung University Dongsan Medical Center, 56 Dalseong-ro, Jung-gu, Daegu 41931, Korea. Tel: +82-53-250-7980, Fax: +82-53-250-7268, E-mail: hikkali@hanmail.net

ORCID: Jae Wook Lee (http://orcid.org/0000-0001-5641-2870); Sung-Moon Lee (http://orcid.org/0000-0002-2675-3209); Dong Gyu Lee (http://orcid. org/0000-0002-4787-4448).

(c) This is an open-access article distributed under the terms of the Creative Commons Attribution Non-Commercial License (http://creativecommons.org/ licenses/by-nc/4.0) which permits unrestricted noncommercial use, distribution, and reproduction in any medium, provided the original work is properly cited. Copyright (c) 2016 by Korean Academy of Rehabilitation Medicine 
necessary to distinguish PNE from pelvic pain of other causes.

In this report, we present the first case of pudendal neuralgia caused by compression from a ganglion cyst around the sacrospinous ligament.

\section{CASE REPORT}

A 60-year-old male presented with a tingling sensation and burning pain in the right buttock and perineal area. The pain was exacerbated while sitting, was rated as 8 on the Numerical Rating Scale (range, 0-10) and was relieved in the supine or standing position.

One month ago, he had visited a local pain clinic to control pain in the right buttock and inguinal area. $\mathrm{He}$ was diagnosed with isthmic spondylolisthesis of L4 on L5 and L5 on S1 as the cause of his pain, and had received multiple spinal epidural steroid injections. However, his pain symptom persisted, and hence he visited our outpatient rehabilitation center.

He had no previous history of illness and trauma. He complained of the above-mentioned symptoms, and had no pelvic organ dysfunction, such as in urination or defecation. On physical examination, the muscle strength and deep tendon reflexes were preserved. He had no definite sensory loss in the right lower extremity. To identify the cause of his pain, we performed pelvis magnetic resonance imaging (MRI), which revealed multiple cysts through the right ischial spine and sacrospinous ligament at the entrance of Alcock's canal. We presumed that this anatomical location of ganglion cyst and pudendal nerve caused pudendal nerve entrapment upon sitting (Fig. 1). Hence, we aspirated about $4 \mathrm{~mL}$ of thick mucoid material under ultrasound guidance (Philips Medical Systems, Bothell, WA, USA) (Fig. 2). His presenting symptom subsided after aspiration, and this improvement was maintained during a 6-month follow-up.

\section{DISCUSSION}

PNE was first described in 1987 by Amarenco et al. [6]. At that time, Dr. Amarenco called it perineal paralysis of cyclists when a cyclist suffering from pudendal neuralgia visited him [6]. The first reported cause of PNE was bicycling, and conditions such as childbirth, direct fall on the tailbone, pelvic surgery, etc., can also cause PNE. The
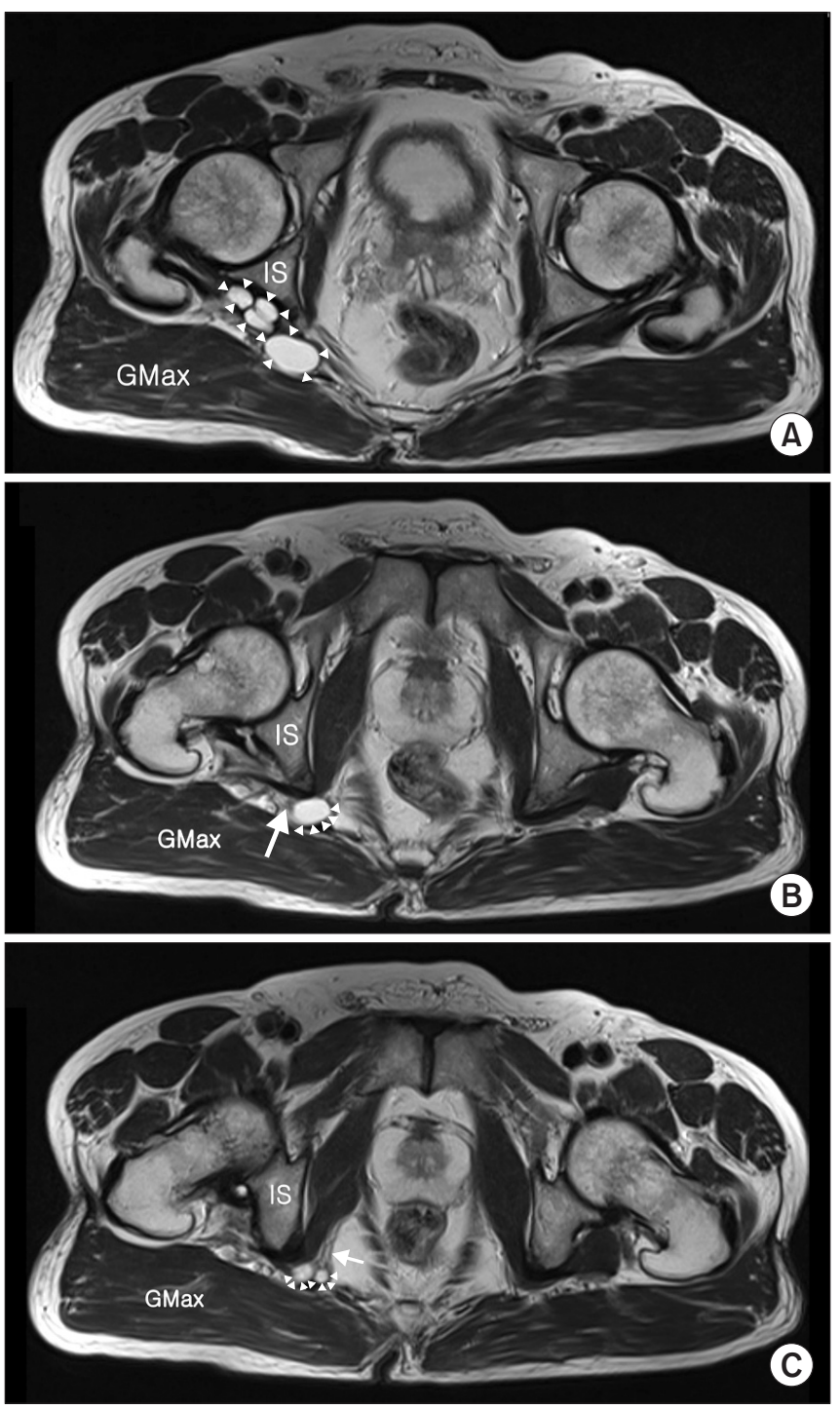

Fig. 1. Axial T2-weighted image showed multiple cystic lesions (arrowheads) through the right ischial spine and sacrospinous ligament (A). Pudendal nerve and vessel bundle (arrow) are located between the ischial spine (IS) and the ganglion cyst at the entrance of Alcock's canal (B) and in Alock's canal passing the ganglion cyst (C). GMax, gluteus maximus.

prevalence of pudendal neuralgia is unknown because it is difficult to diagnose, although Spinosa et al. [7] documented an incidence of $1 \%$ in the general population, with a higher rate in females than males.

Diagnosis of pudendal neuralgia is essentially clinical. In 2008, Labat and his colleagues published 'the Nantes criteria' to facilitate diagnosis of pudendal neuralgia. These include (1) pain in the anatomical territory of the 

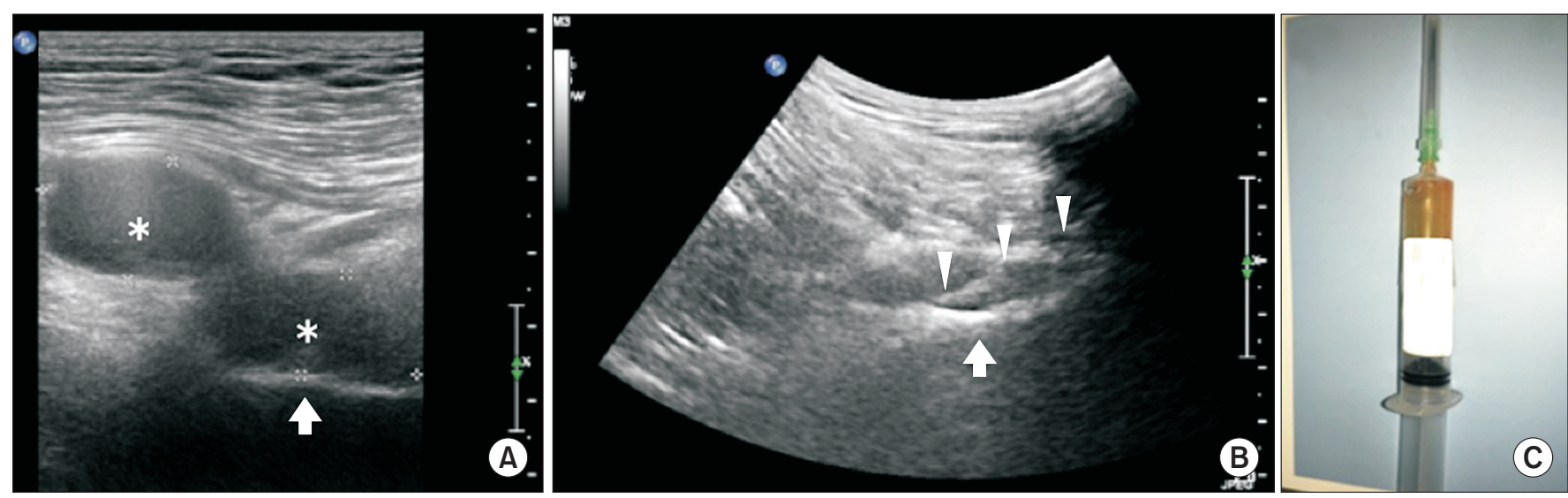

Fig. 2. (A) Ultrasound image obtained using a linear probe showed a bilobed cystic mass (asterisks) in the gluteal area around the ischial bone (white arrow). (B) Long-axis ultrasound image using a round probe guides a 16-gauge spinal needle (arrow head) to the ganglion cystic mass for aspiration. (C) About $4 \mathrm{~mL}$ of thick mucoid material was aspirated.

pudendal nerve, (2) which is worsened by sitting, (3) the patient is not awakened at night by the pain, (4) no objective sensory loss on clinical examination, and (5) positive anesthetic pudendal nerve block. In our case, the patient met four of the Nantes criteria. The fifth criterion was not identified because we did not perform an anesthetic pudendal nerve block. Nevertheless, there are no pathognomonic signs or specific tests for diagnosing pudendal neuralgia and many patients present perplexing symptoms including urinary frequency, pain on a full bladder, and painful bowel movements; hence, diagnosis of PNE is problematic $[2,5]$.

No specific treatment for PNE is available [2,4]. Optional management techniques include physiotherapy, oral medications, pudendal nerve block, and surgical nerve decompression. In general, treatment should begin with a less aggressive measure; i.e., conservative therapy including physiotherapy, oral medications, and sitting pads. Oral medications used include antidepressants, nonsteroidal anti-inflammatory drugs (NSAIDs), anticonvulsants, muscle relaxants, and opioids. When conservative therapy fails, pudendal nerve block with corticosteroids and/or local anesthetics can be applied. After the above-mentioned management techniques do not result in improvement, pudendal nerve decompression surgery is usually considered [4].

A ganglion cyst can arise from any joint or tendon. The most common location is the dorsum of the wrist, followed by the volar aspect of the wrist [8]. In general, a ganglion cyst is asymptomatic, but depending its location and size, may cause nerve root compression or myelopathy $[9,10]$. In the course of the disease, the spontaneous resolution rate of untreated ganglia is $40 \%-58 \%$ [8]. The majority of patients with a ganglion may receive nonsurgical treatments such as aspiration with or without steroids, sclerotherapy, and hyaluronidase therapy. In this case, we aspirated the ganglion cyst without steroids under ultrasound guidance. As a result, the presenting symptom subsided after aspiration and this improvement has been maintained during a 6-month follow-up.

We present herein a case of pudendal neuralgia associated with a ganglion cyst. Pelvis MRI showed multiple cysts located between the right ischial spine and sacrospinous ligament at the entrance of Alcock's canal, which were located close to the course of the pudendal nerve, a frequent location of pudendal nerve entrapment. Moreover, ultrasound-guided aspiration improved the pain during a 6-month follow-up. Hence, we assumed that the ganglion cyst caused entrapment of the pudendal nerve around the sacrospinous ligament. To our knowledge, this is the first case report of pudendal neuralgia caused by a ganglion cyst.

In conclusion, we report the first case of PNE caused by a ganglion cyst. We suggest ultrasound-guided aspiration to be a treatment option to alleviate pain due to pudendal neuralgia caused by a ganglion cyst. However, the recurrence rate of ganglion treated with aspiration alone is $>50 \%$ [8]. Hence, a further study of the utility of ganglion cyst aspiration to control pain due to pudendal neuralgia caused by compression from a ganglion cyst is 
warranted.

\section{CONFLICT OF INTEREST}

No potential conflict of interest relevant to this article was reported.

\section{REFERENCES}

1. Mahakkanukrauh P, Surin P, Vaidhayakarn P. Anatomical study of the pudendal nerve adjacent to the sacrospinous ligament. Clin Anat 2005;18:200-5.

2. Rhame EE, Levey KA, Gharibo CG. Successful treatment of refractory pudendal neuralgia with pulsed radiofrequency. Pain Physician 2009;12:633-8.

3. Elahi F, Callahan D, Greenlee J, Dann TL. Pudendal entrapment neuropathy: a rare complication of pelvic radiation therapy. Pain Physician 2013;16:E793-7.

4. Valovska A, Peccora CD, Philip CN, Kaye AD, Urman RD. Sacral neuromodulation as a treatment for pudendal neuralgia. Pain Physician 2014;17:E645-50.

5. Tagliafico A, Bignotti B, Miguel Perez M, Reni L, Bod- ner G, Martinoli C. Contribution of ultrasound in the assessment of patients with suspect idiopathic pudendal nerve disease. Clin Neurophysiol 2014;125:127884.

6. Amarenco G, Lanoe Y, Perrigot M, Goudal H. A new canal syndrome: compression of the pudendal nerve in Alcock's canal or perinal paralysis of cyclists. Presse Med 1987;16:399.

7. Spinosa JP, de Bisschop E, Laurencon J, Kuhn G, Dubuisson JB, Riederer BM. Sacral staged reflexes to localize the pudendal compression: an anatomical validation of the concept. Rev Med Suisse 2006;2:2416-8, 2420-1.

8. Suen M, Fung B, Lung CP. Treatment of ganglion cysts. ISRN Orthop 2013;2013:940615.

9. Kazanci B, Tehli O, Turkoglu E, Guclu B. Bilateral thoracic ganglion cyst: a rare case report. J Korean Neurosurg Soc 2013;53:309-11.

10. Kim SW, Choi JH, Kim MS, Chang CH. A ganglion cyst in the second lumbar intervertebral foramen. J Korean Neurosurg Soc 2011;49:237-40. 